\title{
Effect of Aluminium Content in Aluminium Pillared Montmorillonite on Its Surface Acidity Properties
}

\author{
Is Fatimah $^{1}$, Narsito $^{2} \&$ Karna Wijaya ${ }^{2}$ \\ ${ }^{1}$ Chemistry Dept., Islamic University of Indonesia, Kampus Terpadu UII, \\ Yogyakarta, Indonesia \\ ${ }^{2}$ Chemistry Dept., Gadjah Mada University, Yogyakarta, Indonesia \\ Email: isfatimah@fmipa.uii.ac.id
}

\begin{abstract}
Aluminium pillared montmorillonites from Indonesian natural montmorillonite has been prepared using $\mathrm{Al}_{13}$ Keggin ion pillaring precursor in varied concentrations. Herein we studied their characterization and catalysis application for esterification reaction. X-ray diffraction (XRD), energy dispersive $\mathrm{x}$-ray analysis (EDX), and BET gas sorption analysis were employed to characterize the prepared materials besides the characterization on surface acidity by pyridine and n-butylammine adsorptions and FTIR analysis. The result showed that significant improvement on physicochemical character data was obtained by a pillarization process. Such a process also provided improvements on catalytic activities in esterification reactions. The effect of aluminium content on material characters was discussed in this paper. It was observed from the catalytic activity tests that pillared montmorillonite samples demonstrated higher activity in esterification reaction relative to the raw montmorillonite. It was found that surface profile of materials consist of specific surface area, pore volume and Lewis acidity were significantly affect the catalyst activity.
\end{abstract}

Keywords: esterification; heterogeneous catalyst; montmorillonite; pillared clay.

\section{Introduction}

Pillared clays are new class of microporous material with high surface areas which have been extensively studied as interesting material in catalysis application. Pillared clays are obtained by insertion of metal oxide in interlayer space of clay structures and firstly prepared in order to improve its thermal stability [1-4]. A calcination process converts cations in the interlayer structure of clays into metal oxide and leads the higher surface area [3-5]. Alumina pillared clays are the most intensive prepared material compared to other transition metals possible to be used in pillarization i.e $\mathrm{Zr}$, $\mathrm{Cr}$, and $\mathrm{Fe}[3,4]$. The Keggin ion $\mathrm{Al}_{13}$ is the responsible polyoxocation intercalating agent which can be synthesized by slow hydrolysis of $\mathrm{AlCl}_{3}$ solution with basic solution. During the calcination step, $\mathrm{Al}_{13}$ intercalant undergoes dehydration and dehydroxylation. It thus transformed into robust $\mathrm{Al}_{2} \mathrm{O}_{3}$ pillars according to the following equation (1):

Received May, $31^{\text {st }}, 2010$, Revised October $18^{\text {th }}, 2010,2$ nd Revision October $31^{\text {st }}, 2010$, Accepted for publication March $13^{\text {th }}, 2011$. 


$$
\left[\mathrm{AlO}_{4} \mathrm{Al}_{12}(\mathrm{OH})_{24}\left(\mathrm{H}_{2} \mathrm{O}\right)_{12}\right]^{7+} \longrightarrow 6.5 \mathrm{Al}_{2} \mathrm{O}_{3}+7 \mathrm{H}^{+}+20.5 \mathrm{H}_{2} \mathrm{O}
$$

A schematic representation of clay pillarizations is presented in Figure 1.

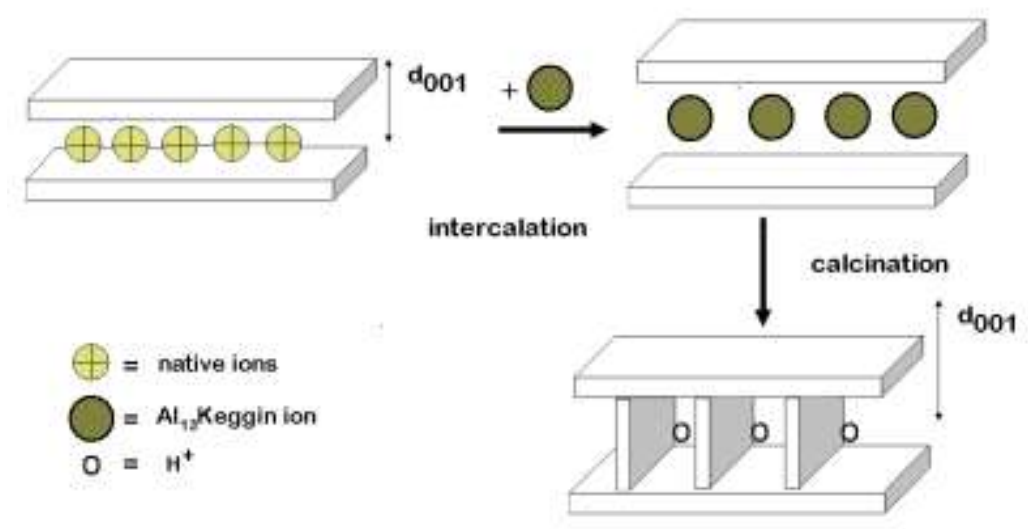

Figure 1 Schematic representation of clay pillarization (adapted from Tomlinson [5]).

The acidity of the materials comes from their pillars. The acidic stability is consistent with its thermal stability and the stability of the surface hydroxy groups. Proton $\left(\mathrm{H}^{+}\right)$generated during the calcination step is one important Brønsted acid contribution besides the Lewis acid site exhibited from aluminium in pillar [6,7]. Considering their recyclability and abundant availability, aluminium pillared clays derived from natural montmorillonites are promising solid-state alternatives to traditional acid catalysts, such as aluminium trichloride, sulfuric acid and hydrofluoric acid. Investigation on the effect of synthesis parameter to the physicochemical character of pillared clays including surface acid properties is the interesting work.

In this paper, preparation and characterization of pillared clay catalyst from Indonesian montmorillonite for esterification reactions are reported. As reported in previous research, some synthesis parameters strongly affect the physicochemical character of pillared clays. Therefore, studies on the parameter optimization for certain application are needed [8-11]. In this study, the effect of aluminium content to the character is focused. Characterizations using XRD, BET and SEM were respectively used to determine crystallinities, interlayer distances of clay structures, specific surface area, pore distribution, and surface performance. Surface acidity as an important property was studied by pyridine and n-butylammine adsorption methods. 


\section{$2 \quad$ Material and Method}

Chemicals used in this research were $\mathrm{NaCl}, \mathrm{H}_{2} \mathrm{SO}_{4}, \mathrm{AlCl}_{3} .6 \mathrm{H}_{2} \mathrm{O}$, ethanol and acetic acid in pro analyst grade which were purchased from E. Merck.

\subsection{Pre Treatment of Materials}

Natural montmorillonite supplied by PT. Tunas Inti Makmur, Semarang, Indonesia was treated by acid activation and homoionization process before pillarizations. In the acid activation, clay slurries were prepared by adding 0.1 $\mathrm{M} \mathrm{H}_{2} \mathrm{SO}_{4}$ solution and was refluxed for $6 \mathrm{~h}$. Solid was separated from the slurry, rinsed with distilled water till the $\mathrm{pH}$ of filtrate reaches 6 and dried in oven overnight. Homoionization process was conducted by mixing dry activated clay with $2 \mathrm{M} \mathrm{NaCl}$ solution followed by stirring for $24 \mathrm{~h}$. Excessive sodium was released by rinsing the sample several times demineralized water.

\subsection{Aluminium Pillarization}

Keggin ion $\mathrm{Al}_{13}$ pillaring precursor was obtained by slow titration of $\mathrm{NaOH}$ into $\mathrm{AlCl}_{3}$ solution under vigorously stirring until the ratio of ${ }^{-} \mathrm{OH} / \mathrm{Al}$ was equal to 2.0 was reached. The solution was kept overnight and dispersed slowly into $2 \%$ clay suspension in water. The dispersion of $\mathrm{Al}_{13}$ solution was varied in 1.0, 2.5, 5 and $10 \mathrm{mmol} \mathrm{Al} /$ gram clay. Each of mixture was kept under stirring at room temperature for $24 \mathrm{~h}$ and then it was separated by filtration and neutralization. The neutralization of clay suspension is an important step in the intercalation process. Such a process was proceeded by continuous rinsing of the suspension with water until the $\mathrm{pH}$ of filtrates reached 6 and the filtrate had been free from $\mathrm{Cl}^{-}$(tested by $\mathrm{AgNO}_{3}$ solution). Finally, solids obtained from this step was dried and calcined at $500^{\circ} \mathrm{C}$. Samples were encoded as PILM-1.0, PILM-2.5, PILM5.0 and PILM-10.0 to indicate the theoric mmol Al contained in a gram of clay.

\subsection{Sample Characterization}

The x-ray diffraction data were obtained by XRD X-6000 Shimadzu difractometer with $\mathrm{Ni}$-filtered Copper $\mathrm{K} \alpha$ radiation, operated at $40 \mathrm{kV}$ and 120 $\mathrm{mA}$. Nitrogen gas sorption analysis for BET isotherm analysis was performed by Quantachrom NOVA 1200e. The elemental analysis consisting Fe, Si, Al and $\mathrm{Na}$ components in the samples was determined by both Scanning Electron Microscope-Energy Dispersive-X ray Flourescence (SEM-EDX) and X-ray Fluorescence. For aluminium determination, the analysis result from SEM-EDX and XRF were confirmed by colorimetric measurement based on UV-Visible spectrophotometric analysis. HITACHI U-2010 spectrophotometer was used for the aluminium analysis by alizarin colorimetric method.

Total acidity of materials was analyzed by pyridine and n-butylammine adsorptions. To measure the total acid number, a half gram of each sample was 
dried in oven at $130^{\circ} \mathrm{C}$ for $5 \mathrm{~h}$ prior to mixing with $0.05 \mathrm{M}$ n-butylammine solution and kept in stirring overnight. The unadsorbed n-butylammine was determined by potentiometric titration with $\mathrm{HCl}$ standard solution. The total acid was defined as an equivalent amount of adsorbed n-butylammine. Brønsted and Lewis acid distribution were measured by pyridine adsorption test of samples followed by FTIR measurement. A half gram of sample was dried in vacuo for $4 \mathrm{~h}$ prior to overnight exposure of pyridine vapor. The process was followed by re-drying of samples through heating at $100^{\circ} \mathrm{C}$ for $1 \mathrm{~h}$. In quantitative, adsorbed pyridine was weighted by microbalance samples indicating the strength of acidity. The Brønsted to Lewis acid distribution was measured by FTIR (as $\mathrm{KBr}$ pellet) using Nicolet AVATAR series FTIR spectrometer.

\subsection{Catalyst Activity Test}

Catalytic activity of prepared pillared montmorillonite was examined by esterification reactions. The reaction was carried out in a three-neck glass reactor $(250 \mathrm{~mL})$ fitted with a condenser and a septum. Ethanol and examined catalyst in the catalyst concentration of $50 \mathrm{mg} / \mathrm{L}$ were placed in the reactor and heated. Once the reflux temperature of ethanol solution was obtained, $50 \mathrm{~mL}$ of acetic acid $3.5 \mathrm{M}$ was added slowly with the rate of $5 \mathrm{~mL} /$ minute through the septum. The kinetics of the reaction was monitored by analyzing acetic acid concentration by volumetric titration. To ensure that the reaction produced ethyl acetate, $40 \mu \mathrm{L}$ of some representative samples were analyzed by high performance liquid chromatography (HPLC) Shimadzu fitted with SE-80 packed column and UV detector. The reacted acetic acid was calculated by formula (1). The conversion of ethyl acetate was calculated as percentage of ethylacetate in using formula (2) based on HPLC chromatogram with an HPLC grade of ethyl acetate standard solution. To calculate the ethylacetate concentration, a linear standard plot of ethylacetate concentration versus peak area in chromatogram was used.

$$
\text { Reacted acetic } \operatorname{acid}(\%)=\frac{[A c]_{0}-[A c]}{[A c]_{0}} \times 100 \%
$$

with:

$[\mathrm{Ac}]_{0}=$ initial concentration of acetic acid $(\mathrm{M})$

[Ac] = measured concentration of acetic acid at time of sampling (M)

$$
\text { Ethyl acetate acid conversion }(\%)=\frac{C_{\text {sample }}}{C_{\text {theoteric }}} \times 100 \%
$$

with: 
$\mathrm{C}_{\text {sample }}=$ ethyl acetate concentration in reaction product

$\mathrm{C}_{\text {theoretic }}=$ theoretic concentration of ethyl acetate based on stoichiometric calculation.

\section{$3 \quad$ Result and Discussion}

Figure 2 presents the XRD pattern of pillared montmorillonites (PILM) with the varied $\mathrm{Al}$ content compared to the raw montmorillonite reflection.

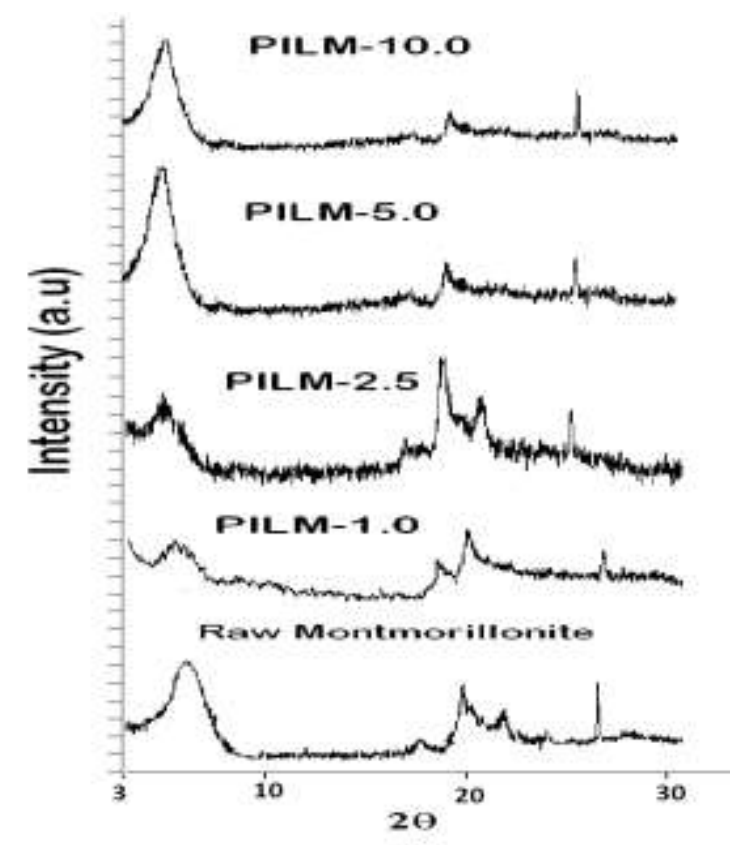

Figure 2 Difractogram of pillared montmorillonites in varied $\mathrm{Al}$ content compared to the raw.

As described in Figure 2, it was found that the raw montmorillonite showed characteristic reflections corresponding to the montmorillonite structure at $2 \theta=$ $6.30^{\circ}$ ([001] reflection) with $\mathrm{d}_{001}=14.47 \AA$ ) and $2 \theta=19.89^{\circ}$ ([002] reflection) with $\mathrm{d}_{002}=4.46 \AA$. Beside, montmorillonite mineral, quartz was also present in the material as shown by reflections responsible for quartz at $2 \theta=20.68^{\circ}$ and $26.5^{\circ}$ with an intensity ratio of $0.2 / 1$. The major reflection of $\mathrm{d}_{001}$ of montmorillonite, depicted at $6.30^{\circ}$ is the most important reflection used for monitoring the success of pillarization. Aluminium pillared montmorillonites showed a shift of $\mathrm{d}_{001}$ reflection toward the lower angle indicating the increase of $\mathrm{d}_{001}$ as a result of $\mathrm{Al}_{2} \mathrm{O}_{3}$ insertion into interlayer space. The effect of 
aluminium content in pillarizations on pillar density numbers, $\mathrm{d}_{001}$ values and full widht at half maximum (FWHM) which corresponds to the pillar distribution of $\mathrm{d}_{001}$ reflection is described in Table 1. Pillar density numbers attributed to the measured aluminium in pillar and FWHM are qualitative parameters to assertain pillar homogeneities.

Table 1 XRD parameters of aluminium pillared clays prepared in this work.

\begin{tabular}{|c|c|c|c|c|}
\hline Sample & $2 \theta$ & $\mathrm{d}_{001}(\mathrm{~nm})$ & FHWM*(nm) & $\begin{array}{c}\text { Pillar Density Number } \\
\left(\mathrm{meq}^{-1} \times \mathbf{1 0}^{-18}\right)\end{array}$ \\
\hline Montmorillonite & 6.3 & $14.392 \pm 0.325$ & 0.550 & - \\
\hline PILM-1.0 & 5.92 & $15.226 \pm 0.782$ & 0.531 & 0.73 \\
\hline PILM-2.5 & 5.56 & $16.195 \pm 0.142$ & 0.852 & 3.36 \\
\hline PILM-5.0 & 5.34 & $17.089 \pm 0.996$ & 0.393 & 3.92 \\
\hline PILM-10.0 & 5.38 & $16.927 \pm 0.582$ & 0.386 & 5.47 \\
\hline
\end{tabular}

Pillar density number is used to measure the uniformity of pillar expressed by the height of intercalated $\mathrm{Al}$ in comparison to the value of initial cation exchange capacity (CEC) [12]. It was observed that the increase of intercalated $\mathrm{Al}$ (in mmol) increased the pillar density number. All pillared montmorillonites showed the significant increase in $\mathrm{d}_{001}$ value. The variation of mole $\mathrm{Al}$ to clay mass in the intercalation process showed that $\mathrm{d}_{001}$ value depended on the $\mathrm{Al}$ content. The $5 \mathrm{mmol} \mathrm{Al} / \mathrm{g}$ clay was considered as the most efective $\mathrm{Al}$ content in the pillarization respective to the highest $\mathrm{d}_{001}$ value and pillar homogeneity. In the range of 1 to $5 \mathrm{mmol} \mathrm{Al} / \mathrm{g}$ of clay, the higher $\mathrm{Al}$ content from intercalated $\mathrm{Al}_{13}$ Keggin ions provides higher $\mathrm{d}_{001}$ value. In general, the more cations are employed in a cation exchange process, the higher exchanged cations may result in. Yet they likely remain constant when they have reached certain conditions due to the limit of cation exchange capacity. This condition is probably the main reason for this phenomenon.

The effect of pillarization to the BET surface area and porosity is given in Table 2.

Table 2 Specific surface areas calculated by BET isotherm and t-plot.

\begin{tabular}{lcccc}
\hline Sample & $\begin{array}{c}\text { Specific } \\
\text { Surface Area } \\
\left(\mathbf{m}^{2} / \mathbf{g}\right)\end{array}$ & $\begin{array}{c}\text { Micropore } \\
\text { Surface Area } \\
\left(\mathbf{m}^{2} / \mathbf{g}\right)^{*}\end{array}$ & $\begin{array}{c}\text { Pore Volume } \\
\left(\mathbf{x 1 0}^{-3} \mathbf{c c} / \mathbf{g}\right)\end{array}$ & $\begin{array}{c}\text { Pore Radius } \\
(\mathbf{\AA})\end{array}$ \\
\hline Montmorillonite & 45.90 & 32.86 & 0.521 & 14.98 \\
PILM-1.0 & 65.25 & 42.09 & 13.445 & 14.99 \\
PILM-2,5 & 114.96 & 65.06 & 18.223 & 14.81 \\
PILM-5.0 & 128.09 & 61.88 & 20.910 & 15.30 \\
PILM-10.0 & 95.98 & 25.96 & 16.765 & 15.08 \\
\hline
\end{tabular}

*: observed by t-plot method 


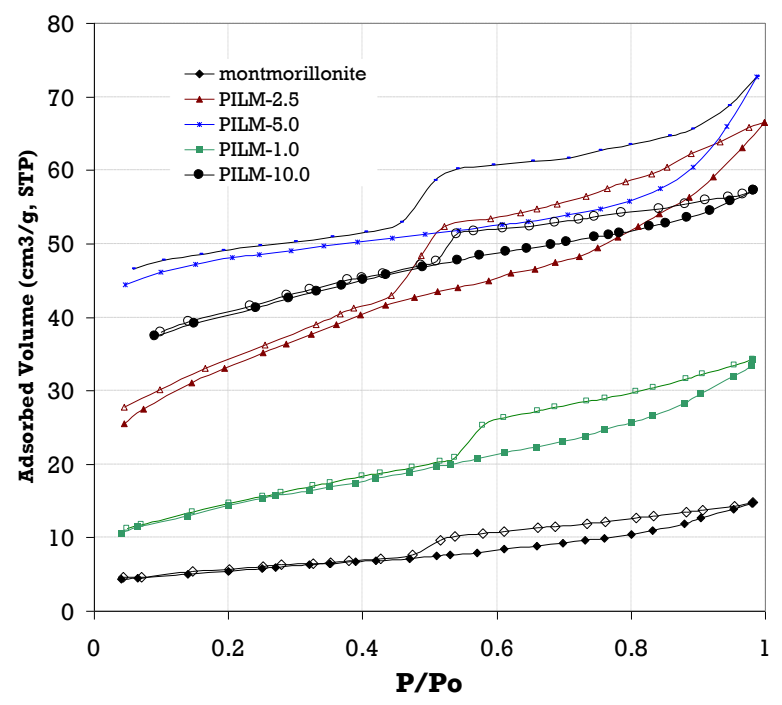

(a)

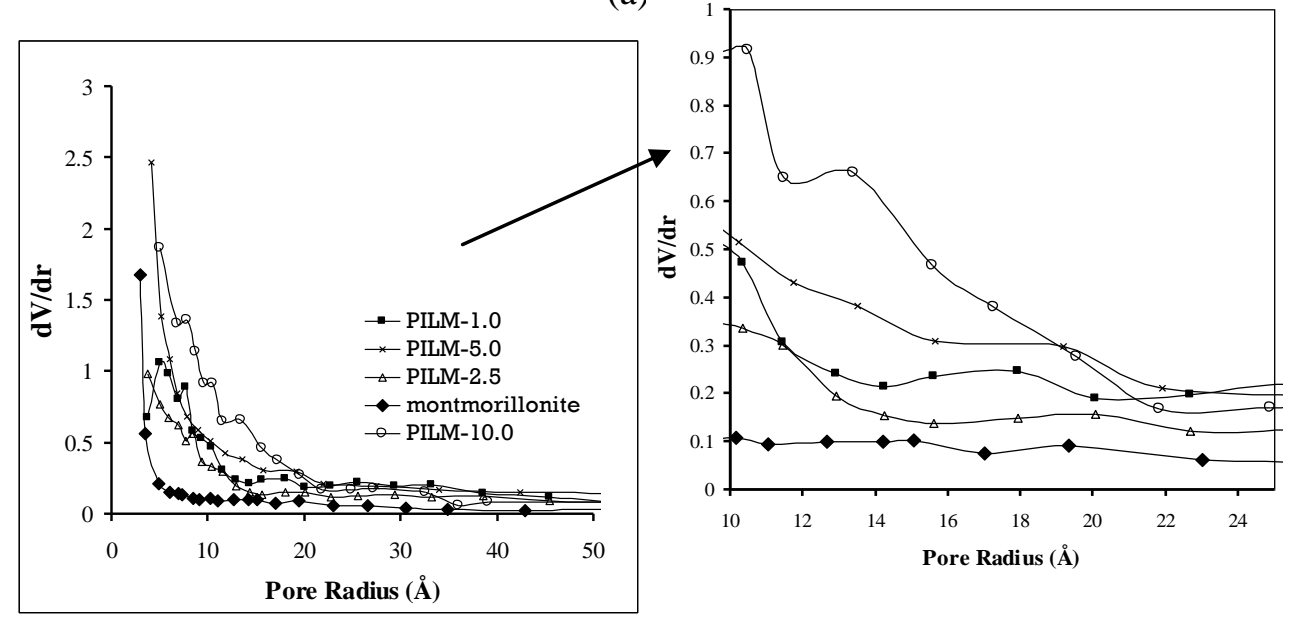

(b)

Figure 3 Comparison on (a) adsorption-desorption profile (b) pore size distribution of raw and pillared montmorillonite.

Changing in BET specific surface areas, pore volume and pore radius of materials are presented as the effect of pillarization. In agreement with the highest $\mathrm{d}_{001}$ evaluated from the XRD data, among other pillared samples, the highest BET surface area is presented by PILM 5.0. Furthermore, the similar pattern of this effect is showed by lower BET surface area, micropore surface area and pore volume of PILM-10 sample compared to PILM-5.0. This may be 
explained by the comparison of adsorption-desorption isotherm and pore distributions profile of raw and pillared materials (Figure 3). Adsorptiondesorption profile (Figure 3a) describes the increase of adsorption capability by pillarization process in all pillared materials which have higher adsorption in all $\mathrm{P} / \mathrm{P}_{\mathrm{o}}$ range. The lower BET surface area of PILM-10.0 compared to PILM-5.0 is also showed as in line with the lower adsorption profile of PILM-10.0.
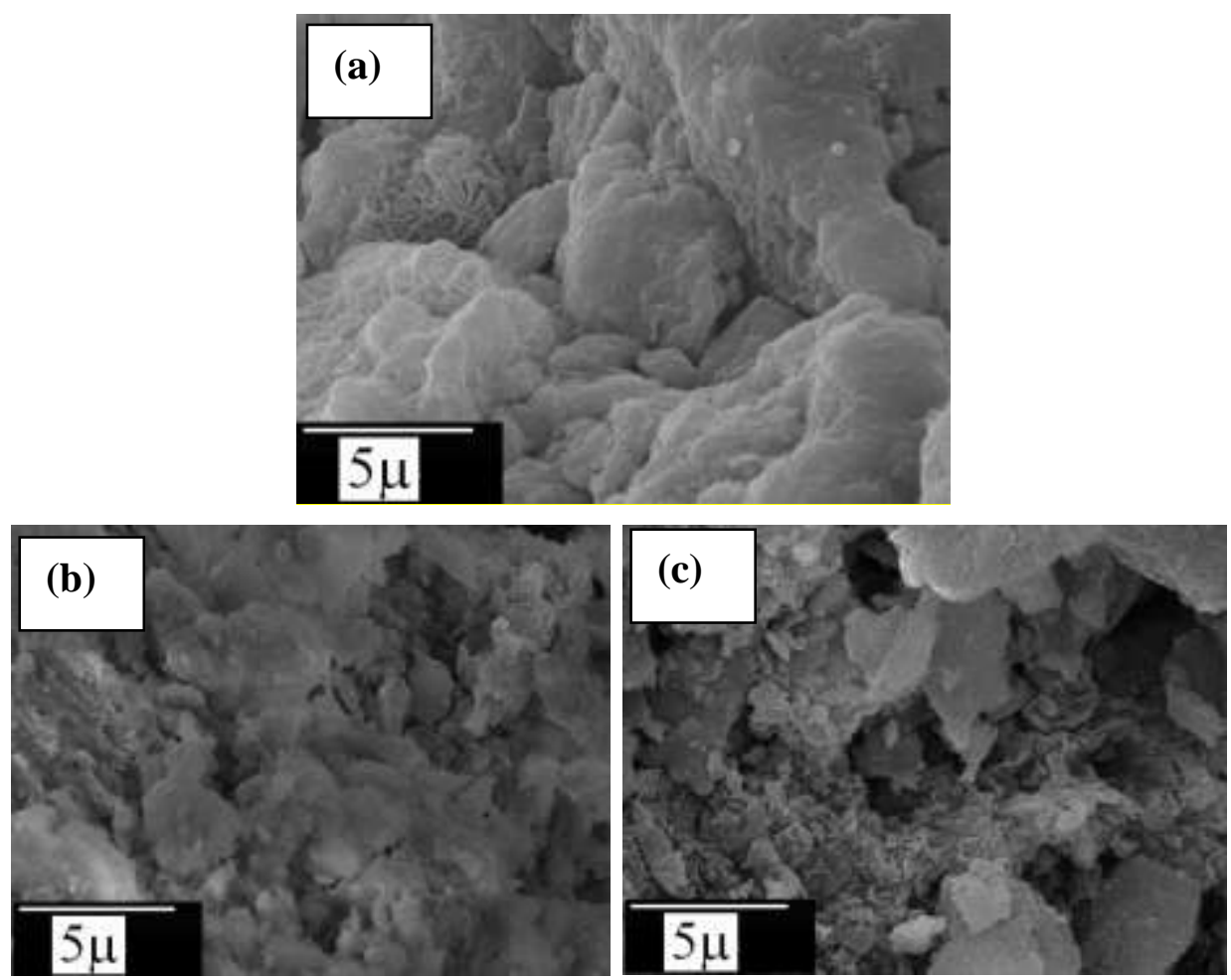

Figure 4 SEM image of (a) Raw Montmorillonite (b) PILM-5.0 (c) PILM-10.0.

Pore distribution in PILM-10.0 sample contained a dominant pore distribution (modal pore) in the radius range of around $10.36 \AA$ and $13.30 \AA$, which were not shown in PILM-1.0 and PILM-5.0 samples (Figure 3b). According to IUPAC definition, such pores are layed at mesoporous range (diammeter of 20$500 \AA$ in size). The pillar density number of PILM-10 was the highest among the samples. But in contrast, the $\mathrm{d}_{001}$ value of PILM-10 was not significantly different with that of PILM-5 ( $\mathrm{d}_{001}$ value of PILM-10 was slightly lower). Previous publications disclosing the effect of metal precursor content in pillared clays explained that the mesoporous formation in PILM-10.0 was likely caused by the formation of house of cards structure $[1,2,13,14]$. 
The modal pores were attributed to the formation of alumina aggregation in interlayer spaces which likely was the reason for the significant decrease of its BET surface area.

Figure 4 presents the SEM profile of the raw montmorillonite and pillared montmorillonites. More opened porous surface was observed in pillared samples compared to the raw montmorillonite (Figure 4). However, the effect of $\mathrm{Al}$ content was not clearly observed. This result is in a good agreement as the one reported in previous work [15]. The rough surface indicated the pillar formation within the structure.

The property of surface acidity in pillared materials is a required character in most catalytic applications such as in esterification reactions. It has been reported that Brønsted acid is the species controlling the kinetics and mechanism of reaction [16]. However, in some cases of heterogeneous catalysts, not only a Brønsted acidity, but also some of physicochemical characters such as Lewis acid species, BET surface area, pore volume and the presence of active sites in surface may give influence to the kinetics efficiency. In this work, role of surface acidity together with other possible factors in esterification reaction were investigated.<smiles>[Y4][n+]1ccccc1</smiles>

(I)<smiles>[M]OC[n+]1ccccc1</smiles>

(II)<smiles>[M]OC[n+]1ccccc1</smiles>

(III)

Figure 5 Possible pyridine species in solid surface.

The acidity strength and acid number in solid acid materials have been reported to be evaluated by pyridine and n-butylammie adsorption method [7, 17]. Total acid number was measured by determining mmole of adsorbed n-butylammine by total acid sites in samples. Brønsted and Lewis acid distribution in surface are measured by pyridine adsorption treatment to materials followed by FTIR analysis to the pyridine adsorbed samples. Theoretically, there are three possible interactions between pyridine and acid site in material surface which correspond to the Lewis acid, Brønsted acid and protonic interaction as hypothesized in previous reports. Three possible interactions is described in Figure 5. 


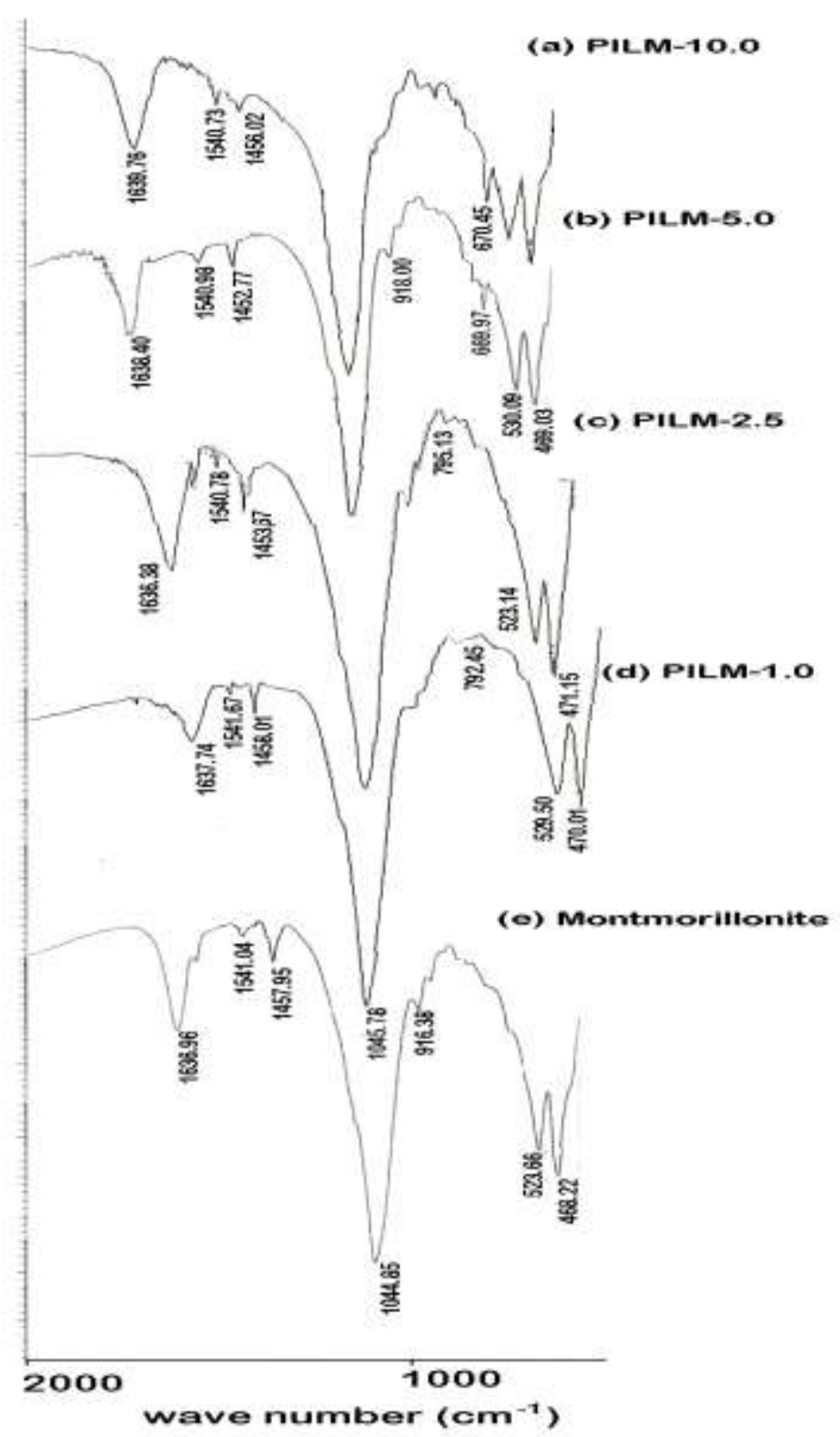

Figure 6 FTIR Spectrum of pyridine-adsorbed materials.

Pyridine species formed through its interaction with solid surface (Figure 5) consist of (i) species I (Lpy), which is formed by coordination bond of free electron pair of nitrogen with the center of Lewis acid sites in surface, (ii) 
species II (Bpy), that is pyridinium ion and formed by protonic $\left(\mathrm{H}^{+}\right)$transfer from $\mathrm{Br} ø$ nsted- $\mathrm{OH}^{2+}$ in surface to pyridine, and (iii) species III (Hpy), that is formed from a hydrogen bonding between nitrogen atom and $\mathrm{OH}^{-}$functional group in solid surface.

Vibration spectra of pyridine are shown at range of $1400-1700 \mathrm{~cm}^{-1}$. Vibration spectrum at $1540-1560 \mathrm{~cm}^{-1}$ is related to the Bpy, and the spectrum at the range of $1450-1455 \mathrm{~cm}^{-1}$ is characteristic for Lpy sites [1]. Beside the quantitative measurement of acid stregth by microgravimetric analysis, the ratio of Lewis to Brønsted acid can be calculated from the ratio of intensity of $1450-1455 \mathrm{~cm}^{-1}$ vibration to the intensity of $1540-1560 \mathrm{~cm}^{-1}$ vibration $\left(\mathrm{I}_{1450-1455 \mathrm{~cm}-1} / \mathrm{I}_{1540-1560 \mathrm{~cm}-1}\right)$. FTIR spectrum of materials after pyridine adsorption treatment is depicted in Figure 6.

FTIR spectra show similarities of some peaks : vibration around $1044 \mathrm{~cm}^{-1}$ which is attributed to $\mathrm{Si}-\mathrm{O}$ tetrahedral also confirmed by the vibration at around $529 \mathrm{~cm}^{-1}$, intense band at around $3460 \mathrm{~cm}^{-1}$ which are indication of skeletal hydroxyl group in clay structure and vibration at around $445 \mathrm{~cm}^{-1}$ which are attributed to $\mathrm{Al}-\mathrm{O}$ bond. What can be noticed from raw montmorillonite and pillared montmorillonite is the shift of vibration corresponds to Al-O and Si-O bands to the higher wavenumber. This suggests that $\mathrm{Al}_{2} \mathrm{O}_{3}$ insertion to clay structures gives higher vibrational energies. The Brønsted and Lewis acid sites are expressed by vibrations at 1550 and $1455 \mathrm{~cm}^{-1}$ respectively.

Calculated Lewis to Brønsted acid ratio and quantitative acidity data are given in Table 3.

Table 3 Total acidity and Lewis/Brønsted acid ratio of materials.

\begin{tabular}{lccc}
\hline \multicolumn{1}{c}{ Sample } & $\begin{array}{c}\text { Solid acidity (mmol } \\
\text { pyridine/gram) }\end{array}$ & $\begin{array}{c}\text { Total Acidity }^{a} \\
\text { (meq/g) }\end{array}$ & $\begin{array}{c}\text { Lewis/Brønsted } \\
\text { Ratio }\end{array}$ \\
\hline Raw Montmorillonite & 0.59 & 0.775 & 0.85 \\
PILM-1.0 & 0.66 & 1.335 & 1.04 \\
PILM-2.5 & 0.66 & 1.110 & 1.07 \\
PILM-5.0 & 0.63 & 1.775 & 1.08 \\
PILM-10.0 & 0.62 & 1.433 & 1.04 \\
\hline
\end{tabular}

${ }^{a}$ calculated by the n-butylammine method

Lewis/ Brønsted ratio was improved due to thepillarization process. The formation of aluminium oxide pillar dominating on clay surface properties resulted in the domination of Lewis acid rather than the Brønsted one. Similar trends were also observed in clay pillarization with $\mathrm{Ti}$ and $\mathrm{Zr}$ metal [3]. 


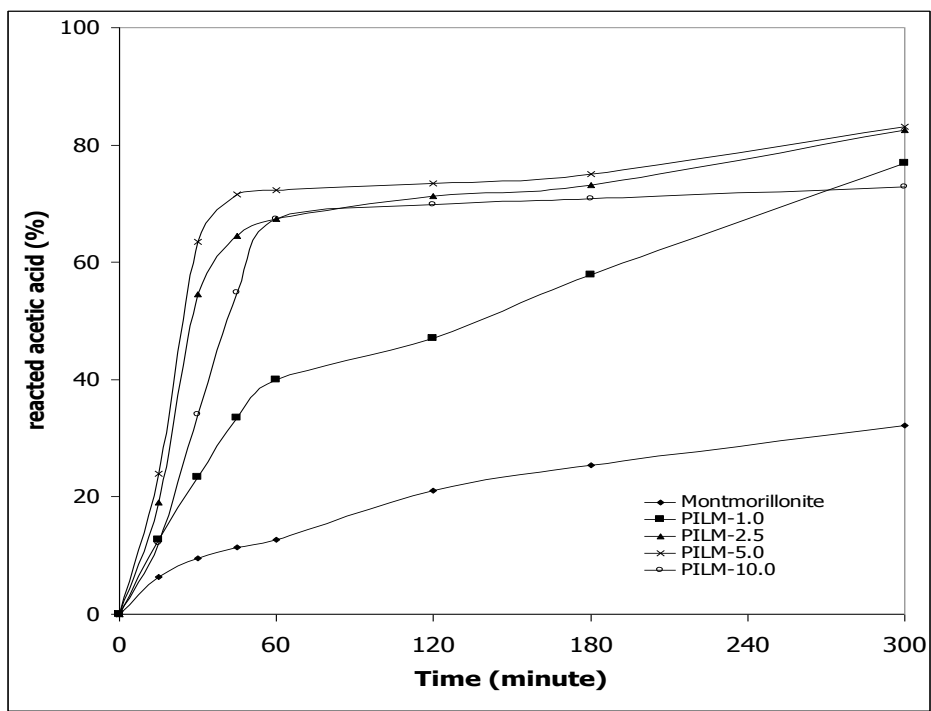

(a)

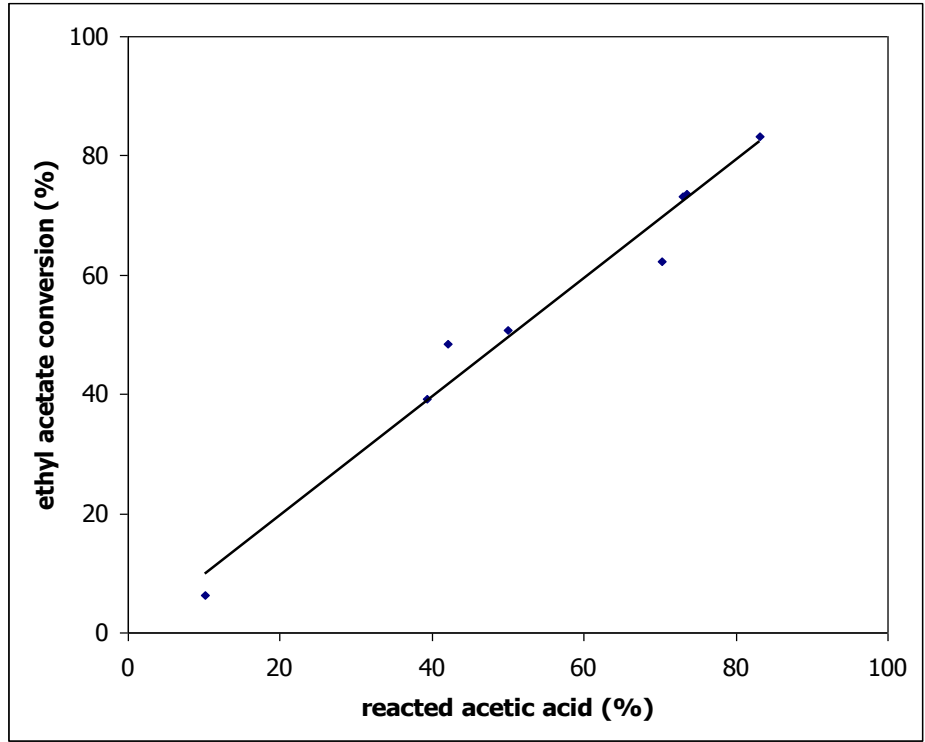

(b)

Figure 7 (a) Kinetic curve of reacted acetic acid as function of reaction Time (b) Curve of correlation between reacted acetic acid and ethyl acetate conversion.

Kinetic observation on esterification reactions between ethanol and acetic acid catalyzed by prepared aluminium pillared clays is described by the kinetics of reacted acetic acid as function of reaction time (Figure 7a) and the curve describing the correlation between reacted acetic acid and ethyl acetate 
conversion derived from some representative samples (Figure 7b). The kinetic constant data $(\mathrm{k})$ measured based on reacted acetic acid as function of reaction time are listed in Table 4 . The correlation coefficient of reacted acetic acid with ethyl acetate conversion is 0.9856 which indicates that the reacted acetic acid is in linear correlation with formed ethyl acetate because acetic acid is a limiting reactant.

Table 4 Statistical data of Esterification Kinetic Simulation.

\begin{tabular}{lccc}
\hline \multicolumn{1}{c}{ Catalyst } & $\begin{array}{c}\mathbf{1}^{\text {st }} \text { order } \\
\text { Correlation }\end{array}$ & $\begin{array}{c}\mathbf{2}^{\text {nd }} \text { order } \\
\text { Correlation }\end{array}$ & $\begin{array}{c}\mathbf{2}^{\text {nd }} \text { order Kinetic } \\
\text { constant [M/min] }\end{array}$ \\
\hline Raw Montmorillonite & 0.93478 & 0.928033 & $1.511 \times 10^{-3}$ \\
PILM-1.0 & 0.94825 & 0.925323 & $10.243 \times 10^{-3}$ \\
PILM-2.5 & 0.96611 & 0.982164 & $14.156 \times 10^{-3}$ \\
PILM-5.0 & 0.77244 & 0.889155 & $13.477 \times 10^{-3}$ \\
PILM-10.0 & 0.78065 & 0.834099 & $8.914 \times 10^{-3}$ \\
\hline
\end{tabular}

Kinetics data in Figure 7 and Table 4 were derived from the experiment on esterification reaction of ethanol and acetic acid in the same concentration. Considering the kinetic equation (2)-(4), the kinetic constant can be obtained by evaluating the plot of acetic acid consumed in varied reaction time (equation (5)-(6)).

$$
\begin{aligned}
& \mathrm{CH}_{3} \mathrm{COOH}+\mathrm{C}_{2} \mathrm{H}_{5} \mathrm{OH} \longrightarrow \mathrm{CH}_{3} \mathrm{COOC}_{2} \mathrm{H}_{5}+\mathrm{H}_{2} \mathrm{O} \\
& \left.v=\frac{d\left[\mathrm{CH}_{3} \mathrm{COOC} \mathrm{C}_{2}\right]}{d t}=k\left[\mathrm{C}_{2} \mathrm{H}_{5} \mathrm{OH}\right]^{m}\left[\mathrm{CH}_{3} \mathrm{COOH}\right]^{n}\right]
\end{aligned}
$$

Since $\left.\left[\mathrm{C}_{2} \mathrm{H}_{5} \mathrm{OH}\right]=\left[\mathrm{CH}_{3} \mathrm{COOH}\right]\right]$

$$
v=\frac{d\left[\mathrm{CH}_{3} \mathrm{COOC}_{2} \mathrm{H}_{5}\right]}{d t}=k\left[\mathrm{CH}_{3} \mathrm{COOH}\right]^{n}
$$

With $m$ and $n$ are order reaction of ethanol and acetic acid respectively.

Kinetics equation for first order and second order reactions are as follow:

$$
\begin{aligned}
& \ln \frac{\left[\mathrm{CH}_{3} \mathrm{COOH}\right]}{\left[\mathrm{CH}_{3} \mathrm{COOH}\right]_{0}}=-k t \\
& \frac{1}{\left[\mathrm{CH}_{3} \mathrm{COOH}\right]_{t}}=k t+\frac{1}{\left[\mathrm{CH}_{3} \mathrm{COOH}\right]_{0}}
\end{aligned}
$$


From the data listed in Table 4, what can be concluded is that all catalyzed reaction obey the second order reaction as showed by higher correlation value of simulated $2^{\text {nd }}$ order reaction compared to the $1^{\text {st }}$ order reaction. There are significant improvements in reaction rate when pillared materials were employed as catalyst compared to the raw sample.

To get more information on the dominated character controlling the kinetics, Pearson Correlation analysis was conducted to evaluate the effect of BET surface area, pore volume, total acidity, Brønsted acidity, Lewis acidity and aluminium pillar density number on the kinetic constant values. The result of this analysis is presented in Table 5.

Table 5 Result of Statistical Analysis: Pearson Correlation on Effect of Physicochemical Character to the Esterification Kinetic Data.

\begin{tabular}{cc}
\hline Factor & Pearson Correlation \\
\hline BET Surface area & 0.8665 \\
Micropore Surface Area & 0.7589 \\
Pore Volume & 0.9467 \\
Total Acidity & 0.8150 \\
Brønsted Acidity & -0.2477 \\
Lewis Acidity & 0.9385 \\
\hline
\end{tabular}

Based on the Pearson correlation data given in Table 5, it is described that Brønsted acidity is not the determining factor in improving kinetics data on esterification reactions. Surface area profiles consisting of specific surface areas, micropore surface areas, and pore volume apparently give more influence to the kinetics. In contrast to the theoretical concept, in this report Lewis acidity is strongly affecting the reaction rate. The result of esterification reaction by raw clay and pillared clays demonstrated that it was not only the surface acidity which controlled the reaction rate, but also surface profiles.

\section{Conclusions}

In this research, aluminium pillared montmorillonite was successfully prepared through ion exchange process of Keggin ion $\mathrm{Al}_{13}$ pillared precursor in varied concentrations. Here we observed that different aluminium contents gave different physicochemical characters. Specific surface area, basal spacing $d_{001}$ of clay structure and surface acidity were clearly identified as important characters for catalytic esterification which were improved by pillarization process of the parent clay with aluminium. It has been reported that aluminium pillar density is controlled by cation exchange capacity of the parent clay. In agreement with this concept, we found that pillarization with $5 \mathrm{mmol} \mathrm{Al} / \mathrm{g}$ of montmorillonite gave the highest value in $\mathrm{d}_{001}$, specific surface area and surface acidity. Studies 
on the effect of these characters give the conclusion that surface profile characters of the material play important role in esterifications reaction of ethanol and acetic acid.

\section{Acknowledgement}

Authors gratefully thank to LPPM UGM for financial support to this research through Hibah Penelitian Mahasiswa Doktor 2009.

\section{References}

[1] Gil, A. \& Gandia, L.M., Recent Advances in the Synthesis and Catalytic Applications of Pillared Clays., Catal. Rev-Sci. Eng., 42(1\&2), 145-212, 2000.

[2] Kloprogge, J.T., Synthesis of Smectites and Porous Pillared Clay Catalysts: A Review, J.Por.Mat., 5, 5-41, 1998.

[3] Kloprogge, J.T., Duong, L.V. \& Frost, R.L., A Review of The Synthesis and Characterization of Pillared Clays and Related Porous Materials for Cracking of Vegetable Oils to Produce Biofuels, Environ. Geol., 47, 967981, 2005.

[4] Selvaraj, S., Mohan, B.V., Krishna, K.N. \& Jai Prakash, B.S., Pillaring of smectites using an aluminium oligomer: A. study of pillar density and thermal stability, App.Clay.Sci., 10, 439-450, 1996.

[5] Tomlinson, A.A.G., Characterization of Pillared Layered Structures, J.Por.Mat., 5, 259-274, 1998.

[6] Lambert, J.F. \& Poncelet, G., Acidity in Pillared Clays: Origin and Catalytic manifestations, Topic in Catalysis, 4, 45-53, 1997.

[7] Tyagi, B., Chudasama, C. \& Jasra, R., Characterization of Surface Acidity of an Acid Montmorillonite Activated with Hydrothermal, Ultrasonic and Microwave Techniques, App.Clay.Sci, 31, 16-28, 2006.

[8] Molina, R., Moreno, G. \& Poncelet, Al-pillared Hectorite and Montmorillonite Prepared from Concentrated Clay Suspensions: Structural, Textural and Catalytic Properties, Studies in Surface Science and Catalysis, 130(2), 983-988, 2000.

[9] Kumar, P., Jasra, R.V. \& Bhat, S.G.T., Effect Of OH/Al Ratio of Pillaring Solution on The Texture and Surface Acidity of Aluminium Pillared Clays, Indian Journal of chemistry. Sect. A: Inorganic, Physical, Theoretical \& Analytical, 36(8), 667-671, 1997.

[10] Reis, A.S. \& Ardisson, J.D., Exchangeable Ion and Thermal Treatment Effects on Basal Spacings of Al-Hydroxy Pillared Montmorillonites, Clays and Clay Miner., 51(33), 33-40, 2003.

[11] Sergio, M., Musso, M.., Medina, J. \& Diano, W., Aluminum-Pillaring of a Montmorillonitic Clay: Textural Properties as a Function of the 
Starting Mineral Particle Size, Journal of Materials Online, 12(2), 1-6, 2006.

[12] Selvaraj, S., Mohan, B.V., Krishna, K.N. \& Jai Prakash, B.S., Pillaring of Smectites Using an Aluminium Oligomer: A. Study of Pillar Density and Thermal Stability, App.Clay.Sci., 10, 439-450, 1996.

[13] Katdare, P.S., Ramaswamy, V. \& Ramaswamy, A.V., Intercalation of Al Oligomers into $\mathrm{Ca}^{2+}$-montmorillonite using Ultrasonics, J. Mater. Chem., 7(11), 2197-2199, 1997.

[14] Booij, E., Kloprogge, J.T. \& Veen, R.B., Preparation, Structural Characteristics and Catalytic Properties of Large-Pore Rare Earth Element (Ce, La)/A1-Pillared Smectites, Clays. Clay Miner, 44(6), 774 $782,1996$.

[15] Tumol, F. \& Balci, S., Synthesis and Characterization of Al-Pillared Interlayered Bentonites, G.U. Journal of Science, 21(1), 21-31, 2008.

[16] Gu,Y., Shi, F. \& Deng, Y., Esterification of Aliphatic Acids with Olefin Promoted by Brønsted Acidic Ionic Liquids, Journal of Molecular Catalysis A: Chemical, 212, 71-75, 2004.

[17] Yurdakoc, M., Akc'ay, M., Tonbul, Y. \& Yurdakoc, K., Acidity of SilicaAlumina Catalysts by Amine Titration Using Hammett Indicators and FTIR Study of Pyridine Adsorption, Turk J Chem., 23, 319, 1999. 